\title{
Redefinition of Prehospital Area as Critical Target for ST-Elevation Myocardial Infarction Care
}

\author{
_ "Time Is Myocardium" -
}

Hideo Fujita, MD, PhD

O T-elevation myocardial infarction (STEMI) is a lifethreatening disease that is characterized by abrupt thrombotic closure of a coronary artery followed by ischemia of the myocardium, resulting in its infarction, or necrosis. The advent of reperfusion therapy such as primary percutaneous coronary intervention (PCI) or thrombolysis has brought substantial clinical benefit for the acute survival as well as for long-term prognosis of STEMI patients, and has been established as a standard treatment. With the current remarkable development of techniques, skills, and devices of PCI, together with contemporary medications, inhospital mortality has been substantially reduced from almost $25 \%$ to $3-10 \% .{ }^{1}$ However, the degree of reduction in the mortality rate depends on the time period between symptom onset and the first balloon inflation (onset-to-balloon, or OTB time), the prolongation of which is associated with impaired ST-segment resolution, impaired myocardial blush grade, larger infarct size and higher mortality rate. ${ }^{2}$

\section{Article p1764}

In terms of ischemic time before primary PCI, very recent work using a large-scale US National Cardiovascular Data Registry (NCDR) CathPCI Registry demonstrates that a reduction in the patient-specific door-to-balloon (DTB) time by $10 \mathrm{~min}$ is consistently associated with reduction of inhospital deaths by $8 \%$ as well as in the 6-month mortality rate by $6 \%$ using multilevel logistic regression models. ${ }^{3}$

Notably, previous reports of bulk analysis had shown that inhospital mortality rates were seemingly unchanged over time despite shortened overall DTB time, because the increase in the population of patients undergoing primary PCI during the

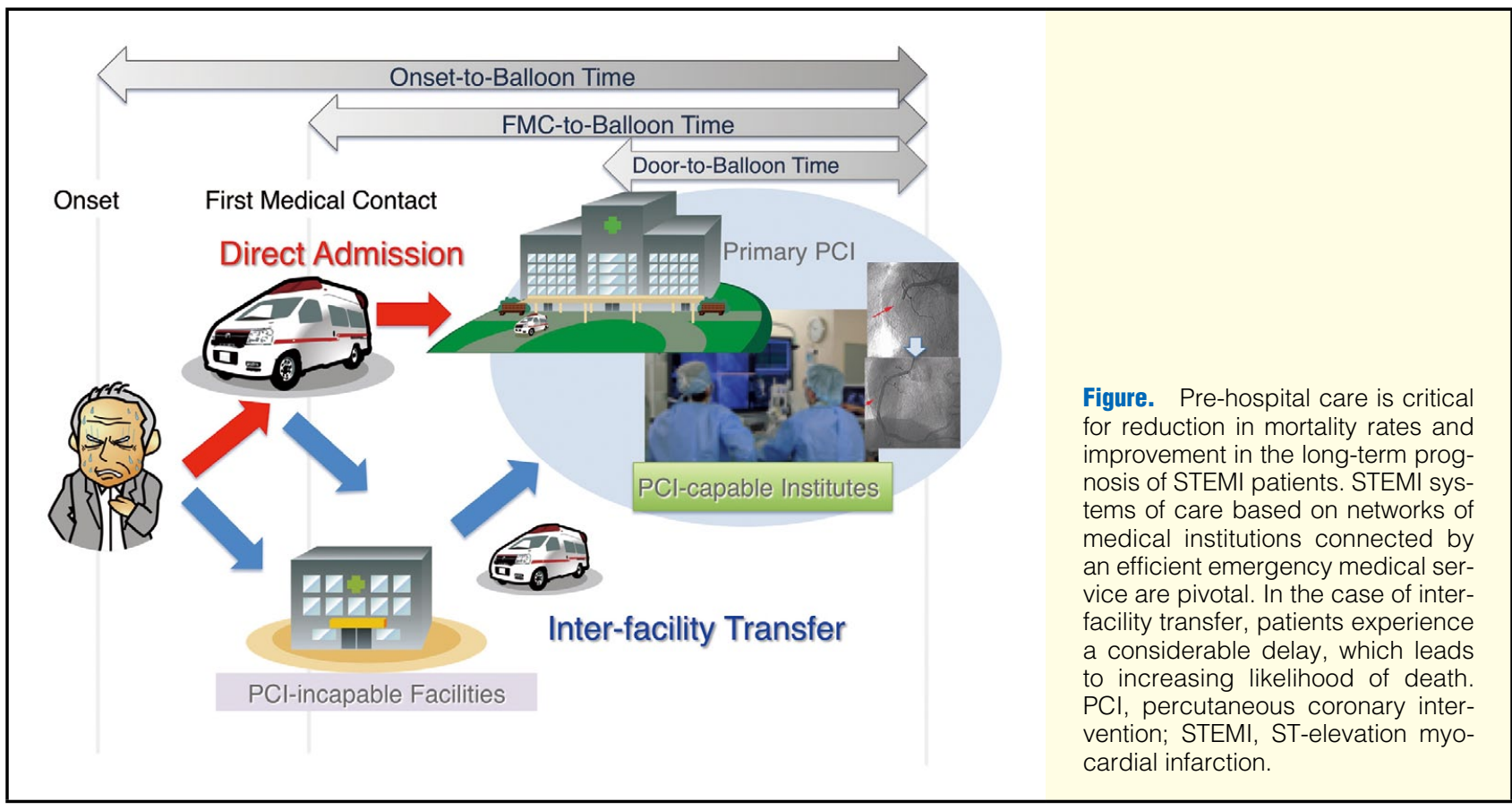

The opinions expressed in this article are not necessarily those of the editors or of the Japanese Circulation Society.

Received June 29, 2016; accepted June 30, 2016; released online July 12, 2016

Division of Cardiovascular Medicine, Saitama Medical Center, Jichi Medical University, Saitama, Japan

Mailing address: Hideo Fujita, MD, PhD, Division of Cardiovascular Medicine, Saitama Medical Center, Jichi Medical University, 1-847

Amanuma, Omiya-ku, Saitama 330-8503, Japan. E-mail: hideofujita@jichi.ac.jp

ISSN-1346-9843 doi:10.1253/circj.CJ-16-0651

All rights are reserved to the Japanese Circulation Society. For permissions, please e-mail: cj@j-circ.or.jp 
study period offset the benefit of DTB time at the population level. ${ }^{4}$ Further, in the previous report from the CREDO-Kyoto study performed in Japan, short OTB time was associated with better 3-year clinical outcomes of the patients with STEMI undergoing primary PCI. ${ }^{5}$

Any regional medical system must seek to enable rapid recognition and timely reperfusion of patients with STEMI (Figure). System delays to reperfusion correlate with higher rates of mortality and morbidity. Although attention to certain performance metrics, such as DTB time and door-in-door-out (DIDO) time, have catalyzed important institutional quality improvement efforts, broader initiatives at a systems level are required to reduce the total ischemic time that is the principal determinant of outcome. ${ }^{6-8}$

Hence the importance of time for STEMI outcome should be revisited again with the saying "Time Is Myocardium". 9

In this issue of the Journal, Nakatsuma and colleagues ${ }^{10}$ analyze one of the largest Japanese registries, CREDO-Kyoto, to compare long-term clinical outcomes of STEMI patients with direct admission to PCI-capable institutes $(n=2,095)$ with those of patients undergoing inter-facility transfer $(n=1,725)$, and they conclude that inter-facility transfer for primary PCI was associated with significantly longer total ischemic time and worse long-term clinical outcomes. Importantly, the cumulative 5-year incidence of death/heart failure hospitalization was significantly higher for patients with inter-facility transfer than for those with direct admission (26.9\% vs. $22.2 \%$; logrank $\mathrm{P}<0.001$ ), and adjusted risk for death/heart failure hospitalization was significantly higher (adjusted hazard ratio: 1.22, 95\% confidence interval: 1.07 to $1.40, \mathrm{P}<0.001)$ in patients with inter-facility transfer than with direct admission. Furthermore, OTB time (ie, total myocardial ischemic time) was significantly higher in the inter-facility transfer group than in the direct admission group, although DTB time, a frequently used surrogate for ischemic time, was significantly reduced in the inter-facility transfer group, presumably because the provision of prehospital information, including 12-lead ECG, enabled proactive preparation for primary PCI. In their study, as many as $45.2 \%$ of STEMI patients were transferred from referring facilities for primary PCI in Japan, where PCI-capable institutes are particularly available in urban areas. Several previous studies also reported that as many as 20-60\% of STEMI patients were transferred from referral hospitals to PCI-capable institutes for primary PCI. ${ }^{11,12}$ In this context, the current study is a landmark in clarifying the importance of prehospital care that substantially affects the clinical outcome of STEMI patients.

These results also confirmed the importance of OTB time as a keener and more objective marker for total myocardial ischemic time during the STEMI process than DTB time in terms of long-term prognosis, and together add to the growing body of literature suggesting that renewed efforts are needed to reduce OTB time as well as, or rather than, DTB time in order to improve myocardial perfusion and clinical outcomes among patients undergoing primary PCI for STEMI.

To improve the overall clinical outcome of STEMI patients, such efforts will be required as reduction in patient-related delay by continuous education, penetration of transmission or instant sharing of prehospital 12-lead ECG as guidelines suggest, ${ }^{7}$ utilization of the doctor's car, ${ }^{13}$ emergency department bypass based upon prehospital ECG, ${ }^{11,14}$ and considering other factors such as sex differences. ${ }^{15}$

More extensive research and development of the prehospi- tal care is a critical target for better emergency care of STEMI patients.

\section{Disclosures}

H.F. served as a consultant for Mehergen Group Holdings, Inc, and received some remuneration from AstraZeneca, and research funds from Novartis Pharma K.K.

\section{References}

1. Takii T, Yasuda S, Takahashi J, Ito K, Shiba N, Shirato K, et al. Trends in acute myocardial infarction incidence and mortality over 30 years in Japan: Report from the MIYAGI-AMI Registry Study. Circ J 2010; 74: 93-100.

2. Prasad A, Gersh BJ, Mehran R, Brodie BR, Brener SJ, Dizon JM, et al. Effect of ischemia duration and door-to-balloon time on myocardial perfusion in ST-segment elevation myocardial infarction: An analysis from HORIZONS-AMI Trial (Harmonizing Outcomes with Revascularization and Stents in Acute Myocardial Infarction). JACC Cardiovasc Interv 2015; 8: 1966-1974.

3. Nallamothu BK, Normand SL, Wang Y, Hofer TP, Brush JE Jr, Messenger JC, et al. Relation between door-to-balloon times and mortality after primary percutaneous coronary intervention over time: A retrospective study. Lancet 2015; 385: 1114-1122.

4. Menees DS, Peterson ED, Wang Y, Curtis JP, Messenger JC, Rumsfeld JS, et al. Door-to-balloon time and mortality among patients undergoing primary PCI. N Engl J Med 2013; 369: 901-909.

5. Shiomi H, Nakagawa Y, Morimoto T, Furukawa Y, Nakano A, Shirai S, et al. Association of onset to balloon and door to balloon time with long term clinical outcome in patients with ST elevation acute myocardial infarction having primary percutaneous coronary intervention: Observational study. BMJ 2012; 344: e3257, doi: 10.1136/bmj.e3257.

6. Terkelsen CJ, Sorensen JT, Maeng M, Jensen LO, Tilsted HH, Trautner S, et al. System delay and mortality among patients with STEMI treated with primary percutaneous coronary intervention. JAMA 2010; 304: 763-771.

7. O'Gara PT, Kushner FG, Ascheim DD, Casey DE Jr, Chung MK, de Lemos JA, et al. 2013 ACCF/AHA guideline for the management of ST-elevation myocardial infarction: A report of the American College of Cardiology Foundation/American Heart Association Task Force on Practice Guidelines. Circulation 2013; 127: e362-425, doi:10.1161/CIR.0b013e3182742cf6.

8. Imori Y, Akasaka T, Shishido K, Ochiai T, Tobita K, Yamanaka F, et al. Prehospital transfer pathway and mortality in patients undergoing primary percutaneous coronary intervention. Circ J 2015; 79: 2000-2008.

9. Gibson CM. Time is myocardium and time is outcomes. Circulation 2001; 104: 2632-2634.

10. Nakatsuma K, Shiomi H, Morimoto T, Furukawa Y, Nakagawa Y, Ando K, et al; on behalf of the CREDO-Kyoto AMI investigators. Inter-facility transfer vs. direct admission in patients with ST-segment elevation acute myocardial infarction undergoing primary percutaneous coronary intervention. Circ J 2016; 80: 1764-1772.

11. Fosbol EL, Granger CB, Jollis JG, Monk L, Lin L, Lytle BL, et al. The impact of a statewide pre-hospital STEMI strategy to bypass hospitals without percutaneous coronary intervention capability on treatment times. Circulation 2013; 127: 604-612.

12. Le May MR, So DY, Dionne R, Glover CA, Froeschl MP, Wells GA, et al. A citywide protocol for primary PCI in ST-segment elevation myocardial infarction. $N$ Engl J Med 2008; 358: 231-240.

13. Takeuchi I, Fujita H, Yanagisawa T, Sato N, Mizutani T, Hattori J, et al. Impact of doctor car with mobile cloud ECG in reducing doorto-balloon time of Japanese ST-elevation myocardial infarction patients. Int Heart J 2015; 56: 170-173.

14. Bagai A, Jollis JG, Dauerman HL, Peng SA, Rokos IC, Bates ER, et al. Emergency department bypass for ST-segment-elevation myocardial infarction patients identified with a prehospital electrocardiogram: A report from the American Heart Association Mission: Lifeline program. Circulation 2013; 128: 352-359.

15. Hao K, Takahashi J, Ito K, Miyata S, Nihei T, Nishimiya K, et al. Clinical characteristics of patients with acute myocardial infarction who did not undergo primary percutaneous coronary intervention: Report from the MIYAGI-AMI Registry Study. Circ J 2015; 79: 2009-2016. 